Finisterra, XXXVII, 73, 2002, pp. 5-31

\title{
INFLUÊNCIA DA OSCILAÇÃO DO ATLÂNTICO NORTE NO CLIMA DO CONTINENTE EUROPEU E NO CAUDAL DOS RIOS IBÉRICOS ATLÂNTICOS
}

\author{
RICARDO TRIGO ${ }^{1}$ \\ TIMOTHY J. OSBORN ${ }^{2}$ \\ JOÃO CORTE-REAL ${ }^{3}$
}

\begin{abstract}
Resumo - A Oscilação do Atlântico Norte (NAO, North Atlantic Oscillation) representa o principal modo de variabilidade da circulação atmosférica no Hemisfério Norte. Este trabalho pretende estudar a influência deste importante modo de circulação no clima do Atlântico Norte incluindo o continente europeu. Para este efeito utilizam-se os 40 anos (1958-97) de dados provenientes das reanálises do NCEP (National Centres for Environmental Prediction). Os campos de anomalias das diferentes variáveis climáticas são então interpretados com base em diferentes mecanismos físicos (ventos, vorticidade, sistemas depressionários, etc.). O campo das anomalias de temperaturas máxima e mínima são controlados pela advecção de calor pelo campo médio dos ventos. No entanto, existem assimetrias entre os campos de temperaturas máxima e mínima e também entre as fases positiva e negativa da NAO que só podem ser explicadas em termos de balanço radiativo e cobertura nebulosa. O impacte da NAO nos campos da água precipitável e da taxa de precipitação é bastante diferente, sendo o primeiro controlado pelo campo das anomalias da temperatura e o segundo pelo campo das anomalias da vorticidade. O importante papel da nebulosidade nas diferentes fases da NAO é realçado. Finalmente, analisou-se o impacte da NAO nos regimes de três rios internacionais ibéricos, o Douro, o Tejo e o Guadiana. Os resultados confirmam que o caudal destes rios é, em grande medida, modelado pela fase da NAO. Este controlo exercido pela NAO na variabilidade interanual do caudal dos rios portugueses é de grande importância económica dada a dependência de Portugal da energia eléctrica de origem hídrica.
\end{abstract}

Palavras-chave : Oscilação do Atlântico Norte, trajectórias depressionárias, temperaturas máxima e minima, taxa de precipitação, água precipitável, regime fluvial.

1 CGUL, Departamento de Física, Faculdade de Ciências da Univ. de Lisboa e Departamento de Eng. Civil da Universidade Lusófona, Lisboa, Portugal. E-mail: rtrigo@fc.ul.pt

2 Climatic Research Unit, University of East Anglia, Norwich, United Kingdom.

3 Centro de Geofísica de Évora, Universidade de Évora, Portugal. 


\begin{abstract}
The impact of the North Atlantic Oscillation on the European Climate AND RIVER Flow OF THREE MAJOR IBERIAN RIVERS - The North Atlantic Oscillation (NAO) is the most dominant mode of atmospheric circulation variability over the entire Northern Hemisphere $(\mathrm{NH})$ and has recently been shown to be related to climate over large regions of the $\mathrm{NH}$, in particular, over the European and North American continents. Here, a multivariable analysis of the influence of the NAO on the climate of the North Atlantic and European sectors is presented using the 40 year (1958-97) reanalysis data set from National Centres for Environmental Prediction. Using high and low NAO index composites, anomaly fields of climate variables are then interpreted based on physical mechanisms associated with the anomalous mean flow (characterised by the surface wind field) and the anomalous eddy activity (characterised by the surface vorticity and the $500 \mathrm{hPa}$ storm track fields). It is shown that NAO-related temperature patterns are mainly controlled by the advection of heat by the anomalous mean flow. However, asymmetries between minimum and maximum temperatures, and more significantly, between positive and negative phases of NAO imply the importance of a different mechanism, namely the modulation of short wave and long wave radiation by cloud cover variations associated with the NAO. Furthermore, NAO influence over two different precipitation-related variables, namely, precipitation rate and precipitable water display different patterns. Precipitable water is shown to be strongly related to the corresponding anomaly fields of temperature while precipitation rate appears to be controlled by the surface vorticity field and associated strength of the tropospheric synoptic activity. Finally, we have assessed the impact of the NAO on winter river flow regimes for several different Portuguese rivers, including the three main international Iberian rivers, the Douro (north), the Tagus (centre) and the Guadiana (south). Results show that the large inter-annual variability of flow of these three rivers is largely modulated by the NAO. Such modulation, associated with the recent positive trend of the NAO index, might implicate a significant decrease of the available flow. This reduction can represent an important hazard for the Portuguese economy due to its negative impact in agricultural yield and hydroelectric power production.
\end{abstract}

Key words : North Atlantic Oscillation, storm tracks, maximum and minimum temperatures, precipitation rate, precipitable water, river flow regime.

\title{
I. INTRODUÇÃO
}

Na última década, verificou-se que a precipitação mensal e em particular a precipitação invernal (Novembro a Março) da Península ibérica é fortemente condicionada por um modo de circulação atmosférica de larga escala, denominado Oscilação do Atlântico Norte ou North Atlantic Oscillation (NAO). Esta oscilação está relacionada com uma alternância da intensidade dos centros de baixas e de altas pressões, que se localizam sobre a Islândia e sobre os Açores (RoGERS, 1984), favorecendo a intensificação (abrandamento) dos ventos zonais de Oeste na fase positiva (fase negativa). Este modo de circulação afecta de forma determinante as trajectórias das principais perturbações sinópticas que atravessam o oceano Atlântico (SERREZE et al., 1997) e condicionam os campos 
da temperatura e da precipitação sobre a Europa. Assim, este modo de circulação atmosférica controla o estado do tempo em toda a Europa (HURRell, 1996; QIAN et al., 2000; TRIGO et al., 2002) e é o factor determinante para o regime de precipitação invernal sobre a Península Ibérica, quer à escala mensal, quer à escala sazonal (Rodó et al., 1997; UlBRICH et al., 1999; GoMES, 2001). Na realidade, a Oscilação do Atlântico Norte (NAO) foi reconhecida há já mais de sessenta anos como correspondendo ao mais importante padrão de variabilidade da circulação atmosférica no Hemisfério Norte (WALKER, 1924; WALKER e Bliss, 1932). No entanto, só muito recentemente este importante modo de circulação tem vindo a ser estudado de forma mais sistemática por climatologistas (ROGERS, 1984; Barnston e Livezey, 1987; HuRrell, 1995; Rogers, 1997). Vários estudos mostraram a importância da NAO no clima invernal de todo o Hemisfério Norte e, em particular, no sector Atlântico/Europa (HurRell, 1995; HurRell, 1996; ROGERS, 1997; QIAN et al., 2000). Outros trabalhos permitiram a identificação de importantes relações entre as diferentes fases da NAO e a actividade sinóptica na zona do Atlântico Norte (SERREZE et al., 1997; OsBorn et al., 1999; Ulbrich et al., 1999). Alguns autores levantam mesmo a hipótese de existir uma relação directa entre as recentes tendências para valores mais elevados tanto do índice da NAO como de temperaturas mais altas no continente euro-asiático (WALLACE et al., 1995; Hurrell, 1996; Hurrell e van LoON, 1997; Thompson e Wallace, 2001). Estes resultados influenciaram um número crescente de estudos baseados em modelos de circulação geral, com o objectivo de reproduzir o padrão da NAO (SARAVANAN, 1998); e a sua influência no clima e nas trajectórias das depressões na região do Atlântico Norte (UlBRICH e CHRISTOPH, 1999; OsBorN et al., 1999). Recentemente, o papel desempenhado pelas anomalias da temperatura superficial do Atlântico Norte na alteração da fase da NAO tem vindo a ser demonstrado com o recurso a conjuntos de simulações de modelos de circulação geral (Rodwell et al., 1999; Metha et al., 2000).

Apesar de o papel da NAO na descrição do clima europeu ser, actualmente, relativamente bem conhecido, a quase totalidade destes estudos tende a restringir-se à análise mensal da temperatura média e da quantidade de precipitação. Em particular, não existe na literatura um estudo simultâneo do efeito da NAO nas temperaturas máxima e mínima, nos ventos à superfície, nas trajectórias dos sistemas depressionários, na água precipitável, na taxa de precipitação diária e na nebulosidade. Da mesma forma, só um número restrito de estudos utiliza explicitamente variáveis de carácter dinâmico que contribuam para a interpretação física da distribuição espacial dos campos de anomalias das variáveis climáticas mencionadas anteriormente, associados com a NAO.

O principal objectivo deste artigo é o de apresentar uma análise tão completa quanto possível do impacte da NAO no clima do continente europeu, utilizando para esse fim, um vasto conjunto de variáveis dinâmicas, características da circulação atmosférica, e de outras relativas ao clima. Um segundo objectivo deste trabalho é o de analisar a magnitude da eventual influência da NAO nos regimes dos principais rios internacionais da Península Ibérica 
(Douro, Tejo e Guadiana). Uma breve descrição dos dados usados bem como da metodologia de compósitos empregue é apresentada seguidamente. Nos pontos III a V são apresentadas análises por compósitos para as duas fases da NAO e relativas às diferentes variáveis climáticas. A interpretação dos mecanismos físicos responsáveis pelos campos de anomalias dessas variáveis é realizada com recurso aos correspondentes campos de anomalias dos ventos e da vorticidade à superfície, da nebulosidade e da actividade sinóptica ao nível dos 500hPa. O impacte da NAO no campo da precipitação na Península Ibérica e no regime dos principais rios de Portugal é tratado no ponto VI. Depois de uma breve discussão dos resultados, algumas conclusões são apresentadas.

\section{DADOS E METODOLOGIA}

Historicamente, a NAO tem sido definida como um simples índice que mede a diferença de pressão à superfície entre Ponta Delgada (Açores) e a estação de Stykkisholmur (Islândia). Esta definição resulta de uma feliz coincidência, a existência de ilhas com postos de medição perto dos dois principais centros que definem este modo de variabilidade da circulação atmosférica. Assim, alguns autores tentaram redefinir o próprio conceito da NAO de forma a que este não fique tão dependente de dados relativos a duas 'simples' estações meteorológicas. Vários autores propuseram a utilização de análise em componentes principais do campo da pressão ao nível médio do mar, de forma a definir os principais centros do dipólo da NAO (WALlaCe e GuTZLER, 1981; BARNSTON e LiVEZEY, 1987). Em particular, WALLACE (2000) afirma categoricamente que, ao contrário das componentes principais, os índices baseados em estações não são representações óptimas da variabilidade temporal dos padrões de circulação a eles associados. No entanto, a análise por componentes principais depende de forma crucial quer da extensão da série temporal utilizada quer da extensão espacial da janela de dados sobre a qual se está a trabalhar. A discussão tem algo de académico, pois um trabalho recente mostrou que os índices da NAO derivados de estações e de uma análise em componentes principais são bastante parecidos (OsBorn et al., 1999), ou seja, referem-se claramente ao mesmo fenómeno de larga escala. Por outro lado, tem sido argumentado recentemente que o padrão espacial associado à primeira componente do campo da pressão ao nível do mar para o Hemisfério Norte inteiro corresponde ao modo AO (Artic Oscillation) e não ao modo mais regional da NAO (THOMPSON e WALLACE, 1998; THOMPSON e Wallace, 2001). Tendo em conta estas dificuldades, foi decidido utilizar-se o índice NAO definido pela diferença das séries de pressão normalizada entre Gibraltar e a Islândia (JoNes et al., 1997). Da mesma forma optou-se pela utilização da definição longa de Inverno, isto é, Dezembro, Janeiro, Fevereiro e

Março. As vantagens destas definições foram descritas pormenorizadamente de forma extensiva em literatura recente (JonEs et al., 1997; OsBorn et al., 1999; TRIGO et al., 2002). 
A maioria dos dados meteorológicos usados neste estudo são dados de larga escala obtidos a partir das reanálises do NCEP para o período 1958-1997. Os dados de reanálises foram obtidos através de um processo consistente de assimilação de dados meteorológicos e de satélite, utilizando um modelo de circulação geral em modo de prognóstico (KALnAY et al., 1996). Valores de 6h em $6 \mathrm{~h}$ relativos à pressão ao nível médio do mar, ao nível do geopotencial aos $500 \mathrm{hPa}$, à água precipitável, à taxa de precipitação, às temperaturas máxima e mínima (a 2 metros de altura) e ao vento zonal e meridional (a 10 metros de altura) foram extraídos para uma rede regular de $2.5^{\circ}$ latitude por $2.5^{\circ}$ longitude, para a área $30^{\circ} \mathrm{N}-80^{\circ} \mathrm{N}$ e $60^{\circ} \mathrm{W}-70^{\circ} \mathrm{E}$. Os dados diários foram então obtidos por uma simples média dos quatro valores horários correspondentes, com a excepção das temperaturas máxima e mínima, para as quais só há, naturalmente, um valor diário. Adicionalmente, valores mensais do campo da nebulosidade entre 1958 e 1995 e de precipitação entre 1901 e 1995 foram obtidos a partir da base de dados de alta resolução $\left(0.5^{\circ}\right.$ latitude por $0.5^{\circ}$ longitude $)$ recentemente desenvolvida pela prestigiada instituição britânica Climatic Research Unit (New et al., 1999; New et al., 2000).

Tendo em conta a utilização extensiva de dados provenientes do projecto de reanálises do NCEP, consideramos necessário tecer alguns comentários sobre as vantagens e desvantagens do uso dos mesmos. A principal vantagem do uso das reanálises em relação às bases de dados registados em redes sinópticas (ou climatológicas) refere-se à possibilidade de se poderem analisar todos os campos que se queiram (dezenas de variáveis a vários níveis), quer sobre os continentes, quer sobre os oceanos. Claro que nem todas as zonas do planeta apresentam a mesma fiabilidade, assim os autores do projecto de reanálises do NCEP definiram uma hierarquia do grau de dependência de cada variável relativamente ao modelo de circulação geral que lhes deu origem. Neste sentido, algumas das variáveis mais difíceis de serem modeladas, como a taxa de precipitação, pertencem ao conjunto de variáveis que estão mais dependentes do próprio modelo, ou seja, mais sujeitas a eventuais erros sistemáticos. No entanto, deve-se realçar que mesmo o padrão da precipitação produzido pelas reanálises apresenta uma qualidade razoável quando comparado com o campo equivalente dos valores observados (STENDAL e ARPE, 1997; Widmann e BRETHERTON, 2000). Finalmente, é necessário ter em consideração o facto de este trabalho utilizar compósitos de campos de anomalias, aos quais foram retiradas as respectivas médias climáticas, removendo assim consideravelmente o impacte de eventuais imperfeições do modelo empregue nos resultados apresentados (TRIGO et al., 2002).

Compósitos de todos os campos mencionados atrás foram definidos para os meses de Dezembro a Março e para o período de 1958 a 1997, utilizando um procedimento semelhante ao de HuRrell (1995). No entanto, ao contrário deste autor, os compósitos relativos a valores elevados e a valores baixos do índice NAO foram obtidos utilizando valores mensais e não sazonais, isto é agruparam-se todos os meses individuais de índice NAO superior a 1 ou inferior a -1 . 
O número de meses com o índice alto da NAO é um pouco superior (64) ao número de meses caracterizado por um índice baixo da NAO (43). Os restantes 53 meses são caracterizados por valores do índice NAO próximos do «normal». $\mathrm{O}$ conhecido padrão da NAO de Inverno corresponde à diferença na pressão entre os compósitos de meses cujo índice NAO $>1.0$ e os meses com índice $\mathrm{NAO}<-1.0$ (fig. 1).

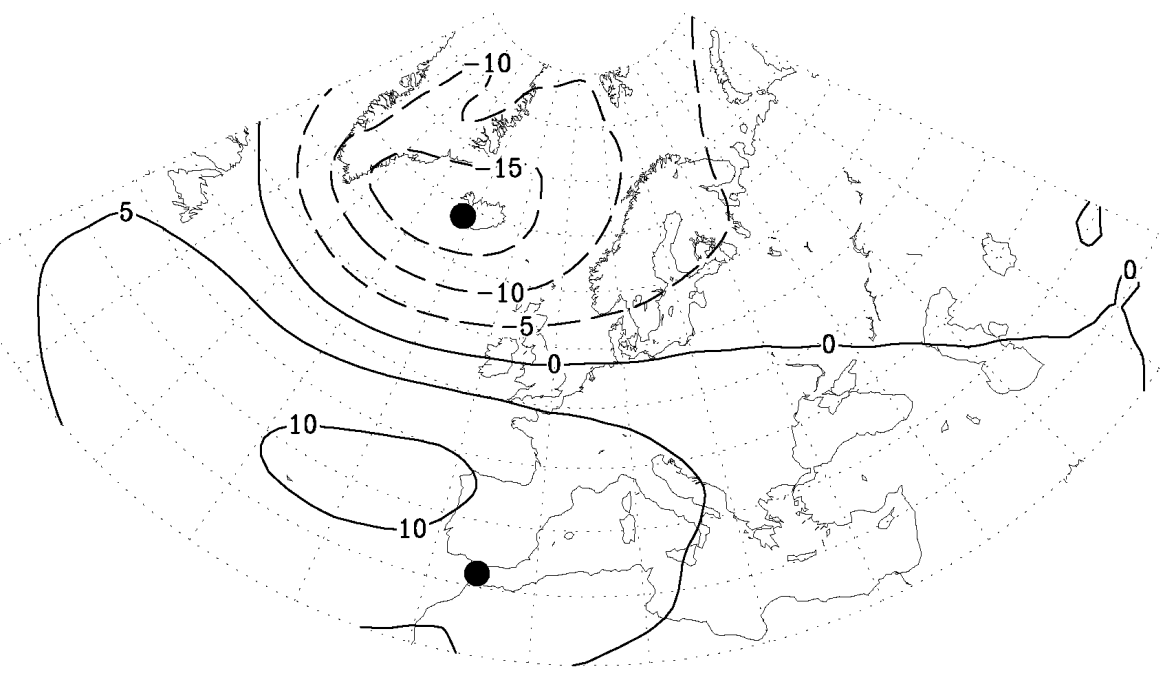

Fig. 1 - Diferença da pressão ao nível médio do mar $(\mathrm{hPa})$ entre os meses de Inverno (DJFM) com índice NAO $>1.0$ e os meses com índice NAO $<-1.0$, relativos ao período compreendido entre 1958 e 1997. Os pequenos círculos a negro representam as estações de Gibraltar e da Islândia.

Fig. 1 -Difference in Sea Level Pressure ( $h P a)$ between winter months (DJFM) with an NAO index $>1.0$ and with an NAO index $<-1.0$ from 1958 to 1997. Small black circles show the location of station observations from Gibraltar and Iceland.

\section{ACTIVIDADE CICLÓNICA E TRAJECTÓRIA DAS DEPRESSÕES}

Na última década, a análise da actividade ciclónica sobre o Atlântico Norte tem vindo a ser realizada essencialmente sob duas perspectivas diferentes:

a) Trajectórias depressionárias. Para o seu estudo, utilizam-se técnicas que incorporam, em geral, algoritmos sofisticados que analisam enormes bases de dados de pressão ao nível médio do mar e permitem detectar as 
principais zonas de desenvolvimento ciclogénico (ciclogénese) e decaimento (ciclólise) assim como as trajectórias de cada depressão individualmente (Murray e Simmonds, 1991; SERreze et al., 1997; Trigo et al., 1999). Em particular, um destes estudos (SERREZE et al., 1997) identificou as trajectórias preferenciais distintas para invernos com índices elevados e baixos da NAO.

b) Actividade sinóptica, analisada através da identificação das zonas de maior variabilidade atmosférica de escala sinóptica através de um filtro "passa banda» que retém a variabilidade atmosférica associada a actividade sinóptica, essencialmente depressões, de escala temporal compreendida entre 2 e 8 dias. Recentemente, esta metodologia foi aplicada a campos de pressão de forma a quantificar a actividade depressionária de escala sinóptica associada aos compósitos de índice elevado e baixo da NAO (Rogers, 1997; HuRREll e van LoON, 1997; Ulbrich e CHRISTOPH, 1999). No presente trabalho optou-se por adoptar esta metodologia.

Dados diários de geopotencial aos 500hPa, entre 1 de Dezembro e 31 de Março e para o período compreendido entre 1958 e 1997, foram tratados por um filtro "passa banda» que maximiza a resposta para periodicidades compreendidas entre 2 e 8 dias (Rogers, 1997). O desvio padrão dos dados filtrados por este processo constitui um óptimo índice proxy da actividade sinóptica em cada ponto da rede. No entanto, é de realçar que esta medida da actividade sinóptica pode ser sensível a outros fenómenos atmosféricos de escala sinóptica que não sistemas depressionários. Assim, os termos relativos a actividade sinóptica ou trajectórias depressionárias são utilizados alternadamente neste trabalho de forma um pouco 'liberal'.

A figura 2 mostra os compósitos dos campos médios da actividade sinóptica para meses de índice NAO elevado (fig. 2a) e índice NAO baixo (fig. 2b). Para meses caracterizados por valores elevados do índice da NAO observa-se um máximo de depressões migratórias entre a Terra Nova e as Ilhas Britânicas. Nos meses de baixo índice NAO este máximo é menos intenso encontrando-se circunscrito à zona da Terra Nova e com extensões de fraca intensidade para Norte (Península Escandinava) e para Sul (Península Ibérica). Tal como seria de esperar, o mapa das diferenças entre os compósitos de alto e baixo índice NAO apresenta uma região de valores máximos centrado a Oeste das Ilhas Britânicas, e um mínimo a Sudeste da Peninsula Ibérica. 

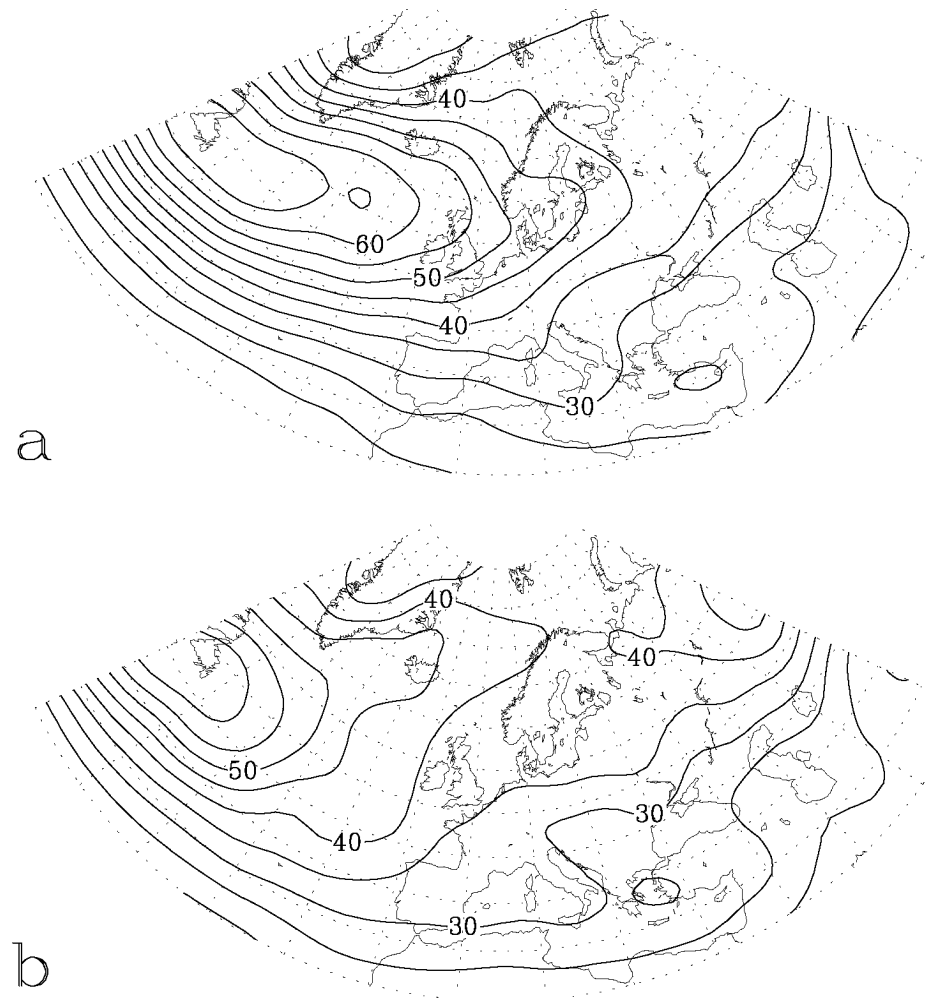

\section{C}

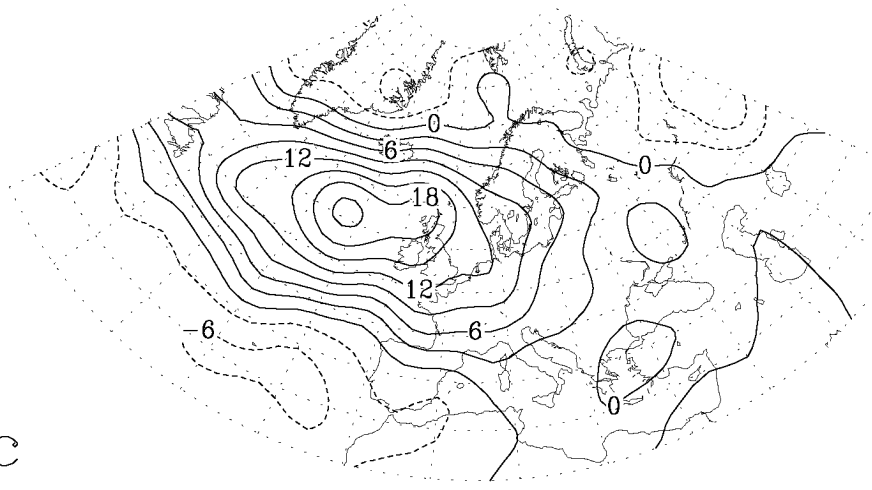

Fig. 2 - Compósitos dos campos de actividade sinóptica (gpm) para os meses de Inverno (DJFM) relativos ao período 1958-1997: (a) índice NAO > 1.0, (b) índice NAO <-1.0 e (c) diferença entre os dois compósitos.

Fig. 2 -Composites of synoptic activity (gpm) for winter months (DJFM) of the 1958-1997 period: (a) NAO index > 1.0, (b) NAO index $<-1.0$ and (c) their difference. 


\section{TEMPERATURAS MÁXIMA (Tmax) E MÍNIMA (Tmin)}

O impacte da NAO na temperatura média da região europeia foi já estudado por vários autores (HuRRell, 1996; OsBorn et al., 1999). No entanto, só muito recentemente surgiram na literatura análises do impacte da NAO nas temperaturas extremas (THOMPSON e WALlACE, 2001; Trigo et al., 2002).

Os campos de anomalias de Tmax para meses de índice NAO elevado e índice NAO baixo podem ser observados nas figuras $3 \mathrm{a}$ e $3 \mathrm{~b}$, respectivamente. Campos equivalentes para Tmin encontram-se nas figuras 4a e 4b. É de salientar que, tanto para Tmax como para Tmin, os campos de anomalias foram obtidos após a subtracção do campo médio de Inverno aos respectivos compósitos de índices alto e baixo da NAO.

Durante a fase positiva da NAO, o gradiente meridional da pressão intensifica-se, contribuindo para um fortalecimento dos ventos de Oeste (ver o compósito dos campos de anomalias dos ventos sobrepostos nas figuras $3 \mathrm{a}$ e 4a). Este significativo incremento dos ventos de Oeste é responsável por uma intensificação da advecção de ar quente e húmido sobre a Escandinávia e Norte da Rússia. Na margem Oeste do Atlântico Norte (Gronelândia) surge, quer para Tmax quer para Tmin, uma vasta área com anomalias negativas como resultado da intensa advecção de ar muito frio proveniente das latitudes polares.

É de realçar que, no caso das temperaturas máxima, este aquecimento estende-se a grande parte da Europa Central, chegando mesmo às regiões da Península Ibérica (fig. 3a); no entanto o mapa equivalente para as temperaturas mínima não apresenta esta extensão para Sul (fig. 4a). Tal como será discutido de seguida a razão desta (e de outras) discrepâncias fica a dever-se à diferente cobertura nebulosa típica das duas fases da NAO. De facto, para meses com elevado índice NAO, a Europa central e a Península Ibérica ficam sob a influência de circulação anticiclónica e, consequentemente, apresentam valores de nebulosidade (fig. 5a) e precipitação (fig. 6a) reduzidas (TRIGO et al., 2002).

Durante a fase negativa da NAO, o gradiente meridional da pressão fica enfraquecido, favorecendo a advecção de ar quente do Atlântico sobre a Terra Nova e Gronelândia, sendo responsável pelas fortes anomalias positivas de Tmax (fig. 3b) e Tmin (fig. 4b) observadas sobre estas regiões. Por outro lado, no sector europeu, a existência de um forte fluxo do ar polar implica um importante transporte de massas de ar frio para o Norte da Europa. No entanto, o impacte deste ar frio continental sobre a Europa do Norte é consideravelmente mais intenso no caso de Tmin do que para Tmax (comparar figuras $3 \mathrm{~b}$ e $4 \mathrm{~b}$ ). Esta assimetria na magnitude da resposta dos campos Tmax e Tmin sobre a Europa resulta igualmente da ausência de nuvens para as circulações sinópticas mais típicas que se encontram associadas à fase negativa da NAO na Europa Setentrional, nomeadamente anticiclones de bloqueio ou circulações de Leste (WILby et al., 1997). Convém lembrar que, em geral, os valores de Tmax são registados de dia e os valores de Tmin durante a madrugada. Assim, durante o dia, a forte radiação solar (de pequeno comprimento de onda) compensa, 

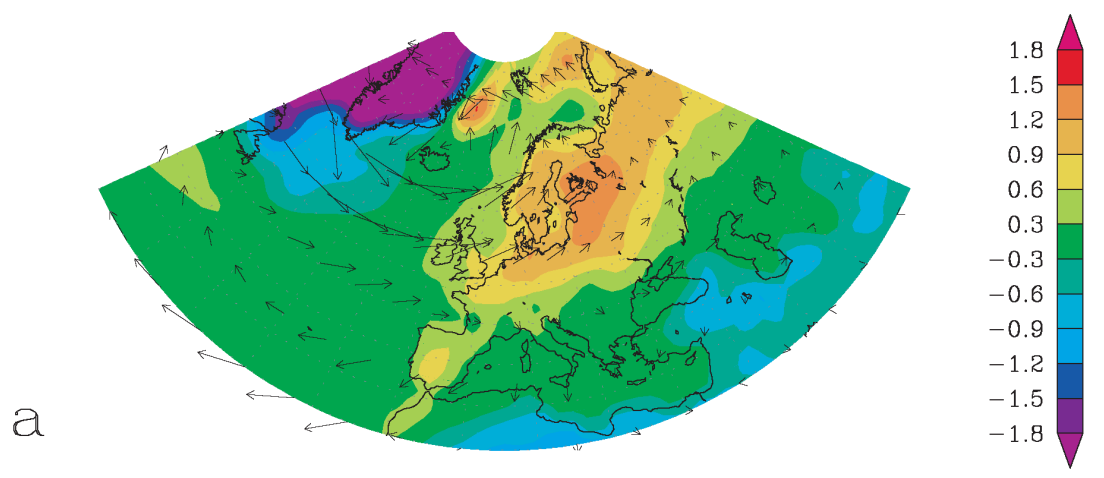

b
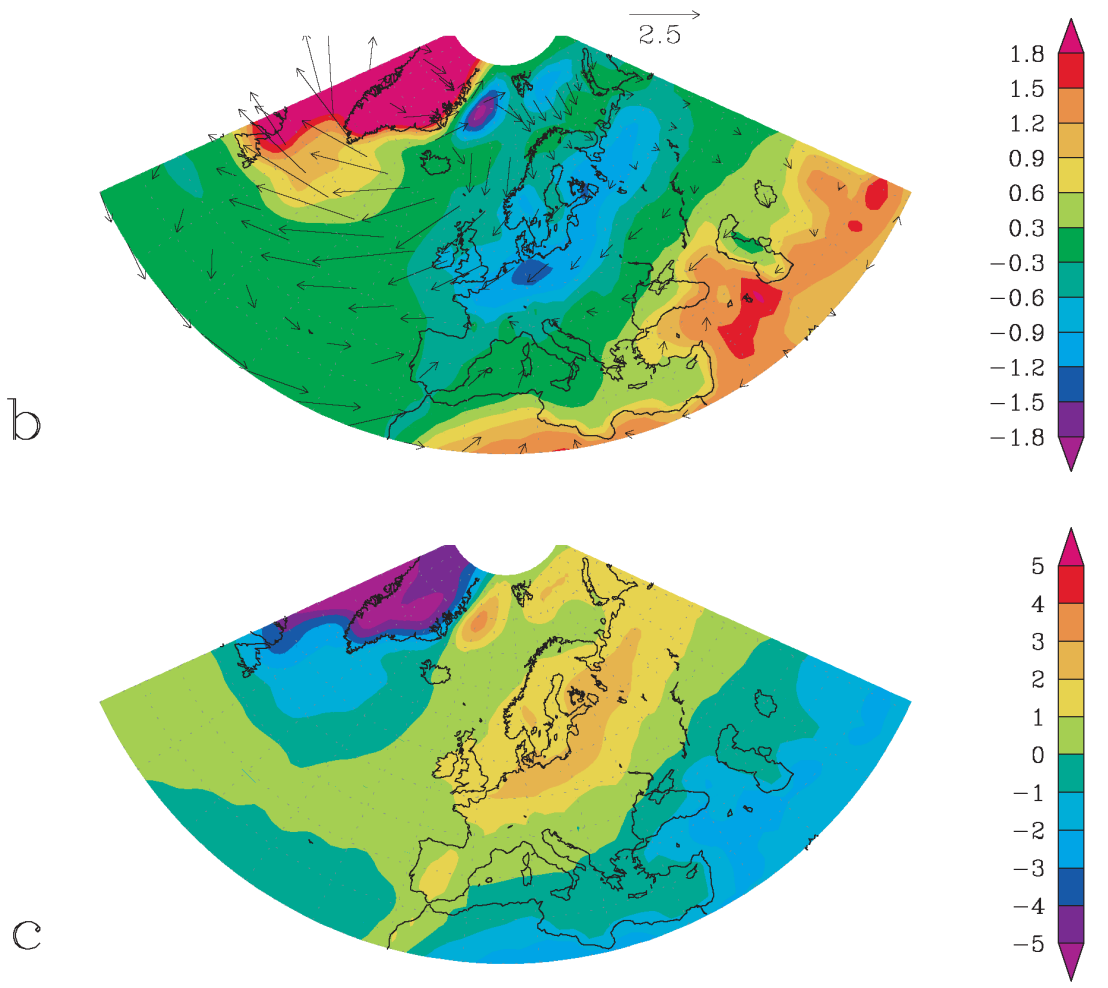

Fig. 3 - Compósitos do campo de anomalias de Tmax $\left({ }^{\circ} \mathrm{C}\right)$ para os meses de Inverno (DJFM) relativos ao período 1958-1997: (a) índice NAO > 1.0, (b) índice $\mathrm{NAO}<-1.0$ e (c) diferença dos dois compósitos. O campo de anomalias dos ventos $(\mathrm{m} / \mathrm{s})$ aos $10 \mathrm{~m}$ de altura também se encontra representado para meses de elevado (a) e baixo (b) índice da NAO.

Fig. 3 -Tmax anomaly fields $\left({ }^{\circ} \mathrm{C}\right)$ for winter months (DJFM) of the 1958-1997 period: (a) high NAO index > 1.0, (b) low NAO index $<-1.0$ and (c) their difference. Vectors of the anomaly $10 \mathrm{~m}$ wind field $(\mathrm{m} / \mathrm{s})$ for months with (a) high and (b) low NAO index are also represented. 
15
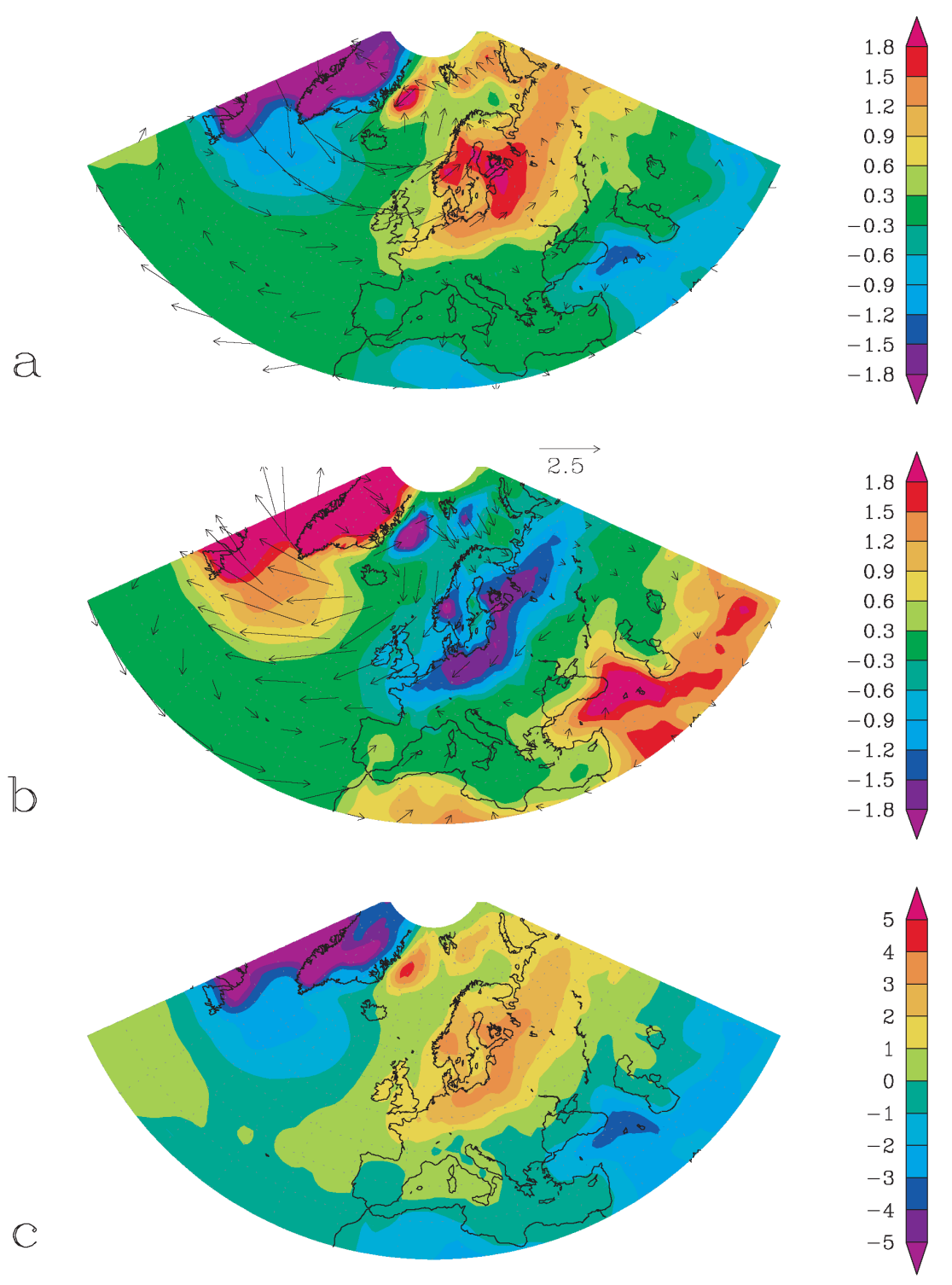

Fig. 4 - Tal como na fig. 3, mas para Tmin.

Fig. 4-The same as in fig. 3, but for Tmin. 

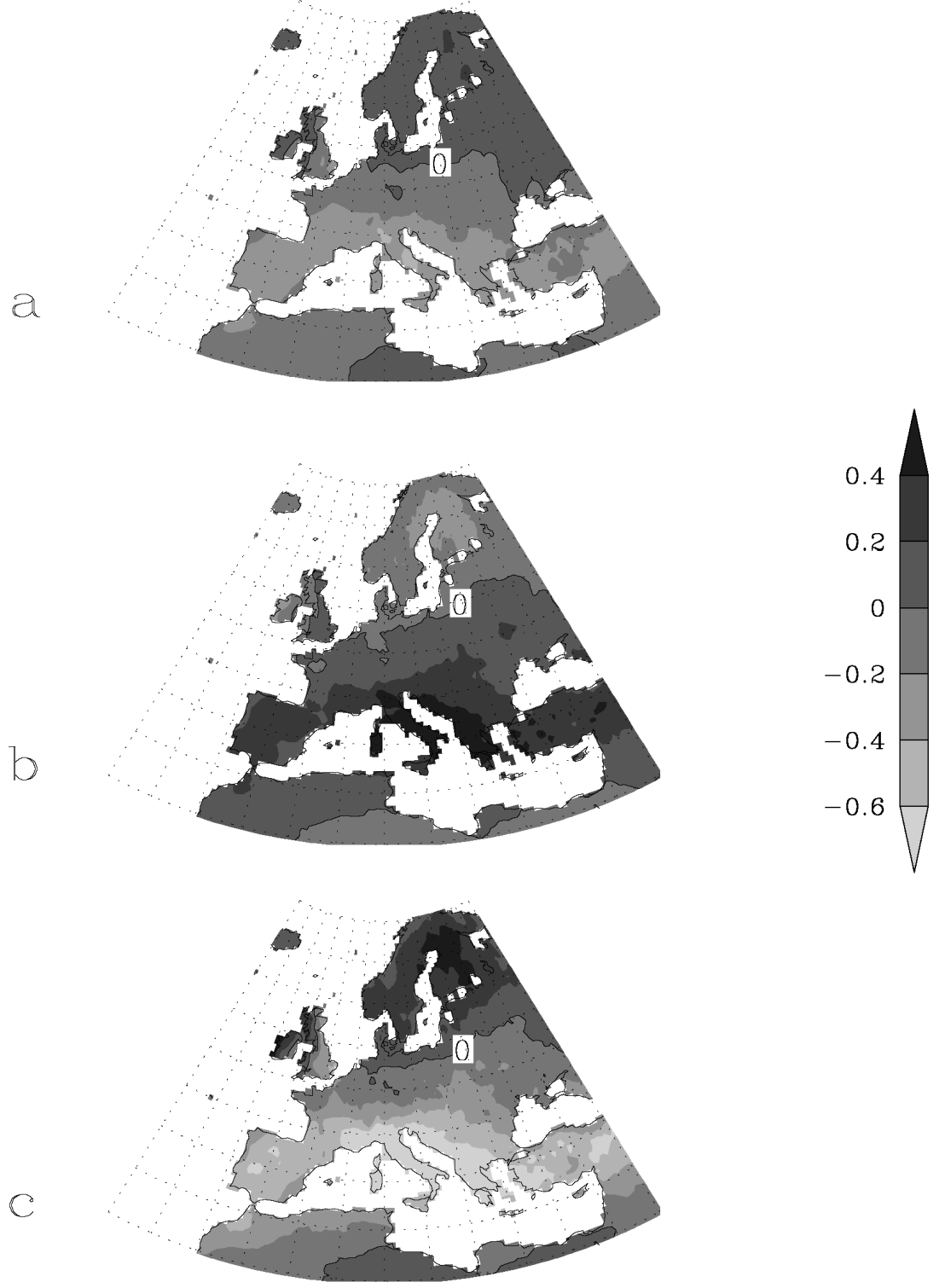

Fig. 5 - Compósitos do campo de anomalias da nebulosidade (oitavos), sobre o continente europeu, para os meses de Inverno (DJFM) relativos ao período 1958-1995: (a) índice NAO > 1.0, (b) índice NAO <-1.0 e (c) diferença entre os dois compósitos.

Fig. 5-Cloud cover anomaly fields (oktas) for winter months (DJFM) of the 1958-1995 period: (a) NAO index > 1.0, (b) NAO index $<-1.0$ and (c) their difference. 
pelo menos parcialmente, a advecção de ar frio polar, limitando a magnitude e extensão das anomalias de Tmax. Já durante a noite, a ausência de céu nublado favorece a emissão de radiação (de grande comprimento de onda) ampliando assim o arrefecimento da baixa camada da troposfera.

A sobreposição dos campos de anomalias do vento a $10 \mathrm{~m}$ nas figuras 3 e 4 permite comprovar resultados de estudos anteriores que justificam o padrão de anomalias da temperatura média como sendo essencialmente imposto pelo transporte de calor pelos correspondentes campos de anomalias da circulação atmosférica (HuRRell, 1996; OsBorn et al., 1999). Outros autores mostraram igualmente o papel das perturbações migratórias no transporte de calor (Hurrell e van Loon, 1997; DeWeaver e Nigam, 2000). No entanto, a análise aqui apresentada põe em evidência a importância de um terceiro processo na modulação da temperatura superficial. Este terceiro processo resulta da modulação da transferência radiativa de calor à superfície da Terra devida às fortes assimetrias dos campos de nebulosidade associados às duas fases da NAO. Esta influência manifesta-se em campos de anomalias com padrões espaciais distintos para a Tmax e Tmin, como resultado de estes valores serem registados em alturas bem distintas do ciclo diário (Trigo et al., 2002).

O campo das diferenças de Tmax (Tmin) para compósitos de elevado e de baixo índice da NAO pode ser observado na figura 3c (fig. 4c). Em ambas as situações, é possível observar diferenças significativas nas regiões do Norte da Europa, da Gronelândia/Terra Nova e na zona do Mar Cáspio. A amplitude das diferenças é nitidamente mais elevada no caso de Tmin.

\section{PRECIPITAÇÃO}

A figura 2 mostra de forma clara que as diferentes fases da NAO são acompanhadas por importantes alterações nas trajectórias médias dos sistemas depressionários (Rogers, 1990; HURRELl, 1995; RogERs, 1997). Estudos anteriores mostraram que tais alterações estão igualmente relacionadas com importantes modificações nos padrões regionais de precipitação sobre grande parte da Europa, Norte de África e mesmo da costa Leste da América do Norte (Hurrell, 1995; Hurrell e van Loon, 1997; Osborn et al., 1999). A análise do impacte da NAO no campo da precipitação na Europa tem sido efectuada quer com base em valores registados em udómetros quer através do balanço hídrico [evaporação menos precipitação (E-P)], calculado a partir de dados provenientes de reanálises (Hurrell, 1995; Hurrell e van Loon, 1997). Apesar de a primeira metodologia estar mais próxima da precipitação 'real', esta técnica sofre de evidentes restrições devido à falta de cobertura de dados sobre os oceanos enquanto a segunda técnica tem a grande vantagem de poder ser aplicada de igual forma sobre os continentes e sobre os oceanos. No entanto, a estabilidade dos resultados apresentados por HURRELl (1995) e HURrell e 

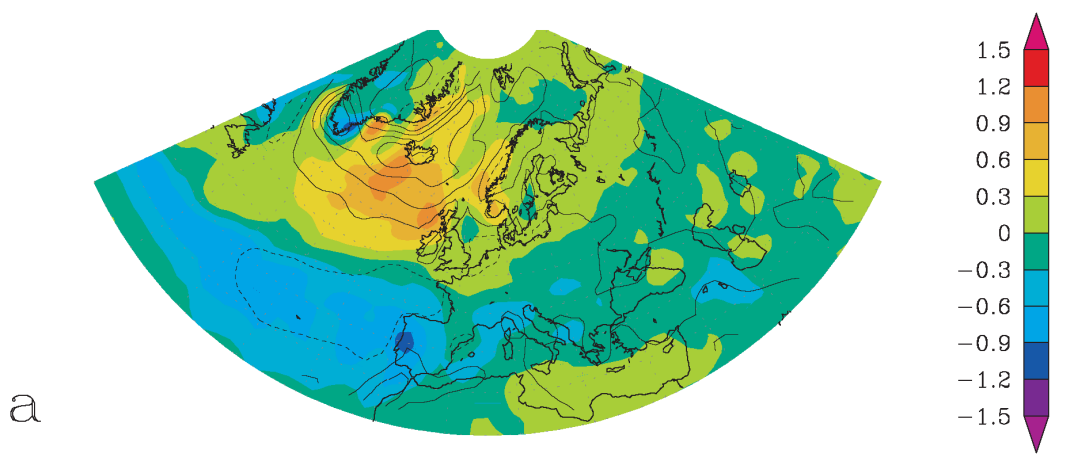

b
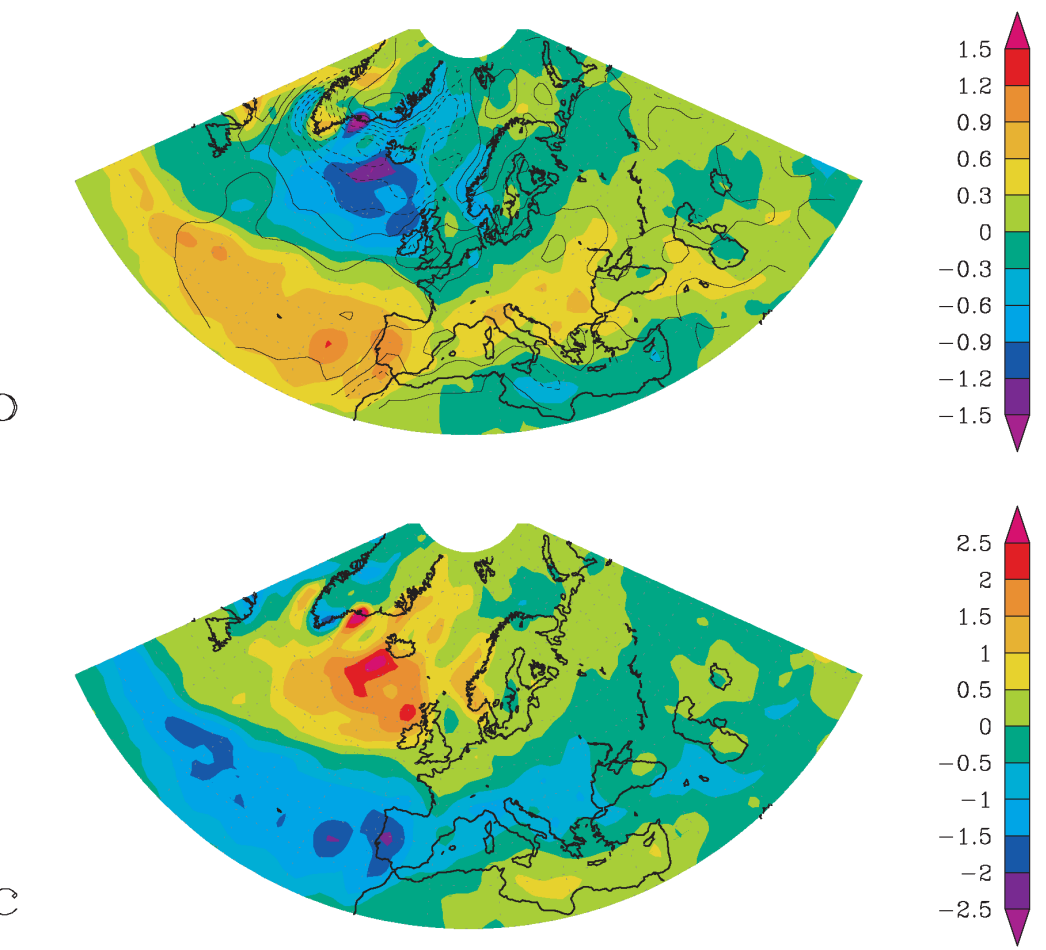

Fig. 6 - Compósitos do campo de anomalias da taxa de precipitação diária (mm/dia) para os meses de Inverno (DJFM) relativos ao período 1958-1997: (a) índice NAO > 1.0, (b) índice NAO < -1 e (c) diferença entre os dois compósitos. Valores positivos (isolinhas a cheio) e negativos (isolinhas a tracejado) do campo da vorticidade aos $10 \mathrm{~m}$ também se encontram representados para meses de índice elevado (a) e baixo (b) da NAO.

Fig. 6 - Precipitation rate (PR) anomaly fields ( $\mathrm{mm} /$ day) for winter months (DJFM) of the 1958-1995 period: (a) high NAO index > 1.0, (b) low NAO index $<-1.0$ and (c) their difference. Positive (solid) and negative (dashed) isolines of the $10 \mathrm{~m}$ anomaly vorticity field for months with (a) high and (b) low NAO index are also represented. 

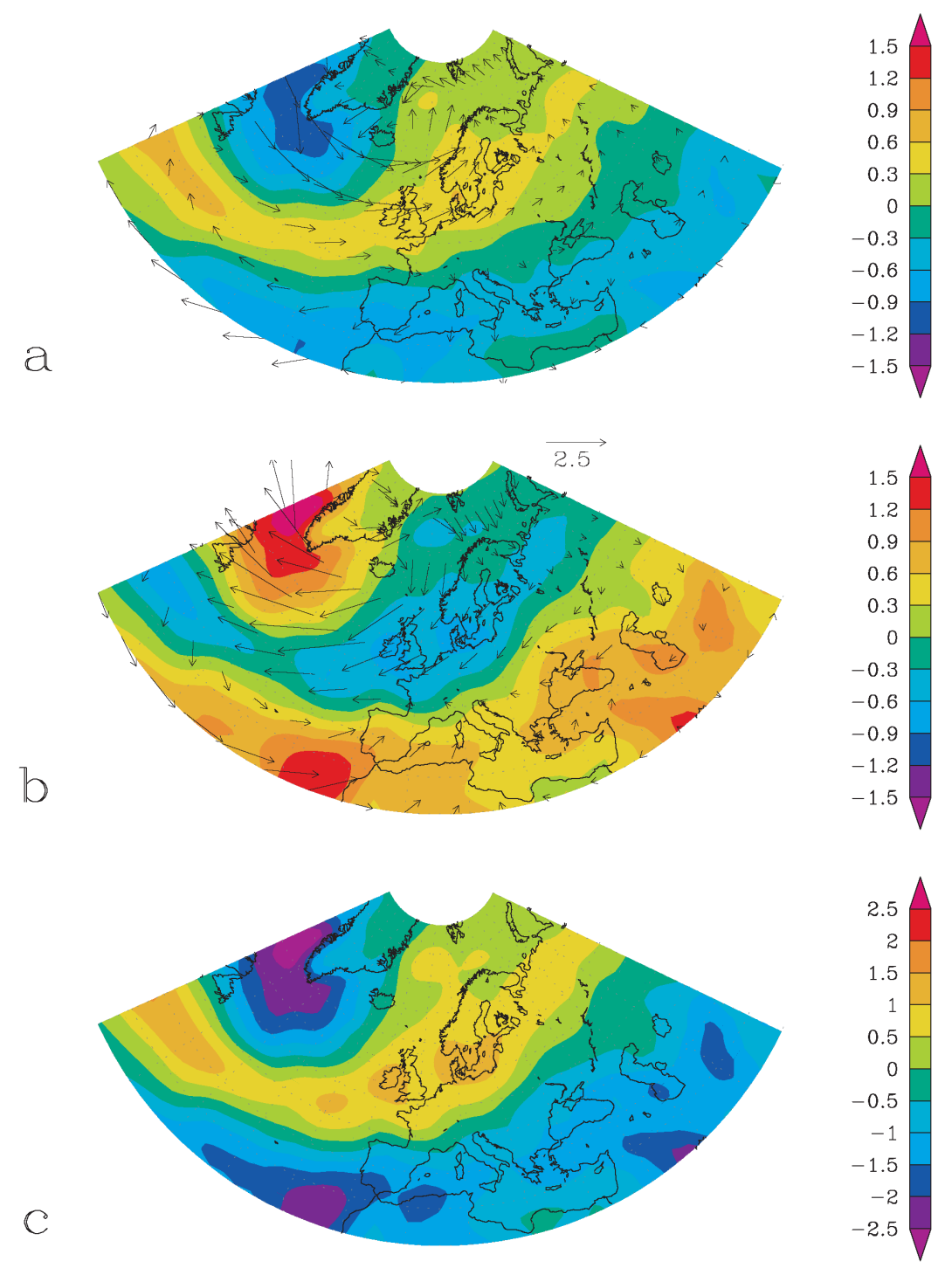

Fig. 7 - Tal como na fig. 6, mas para a água precipitável.

Fig. 7 -The same as in fig. 6, but for precipitable water. 
VAN LOON (1997) parece estar seriamente comprometida em consequência da curta série de reanálises (1979-1993) empregue nesses estudos. De facto, os resultados obtidos por estes autores com as duas metodologias divergem, de forma considerável, sobre certas regiões da Europa. A extensão das reanálises desenvolvidas pelo NCEP ajudam a minorar consideravelmente este problema pois utilizam um período de dados globais e consistentes de quarenta anos (TRIGO et al., 2002).

Os campos de anomalias da taxa de precipitação diária para meses de índice NAO elevado e índice NAO baixo podem ser observados nas figuras $6 \mathrm{a}$ e 6b, respectivamente. Ambas as figuras apresentam bandas quase-zonais de anomalias de sinais opostos, sendo este facto reforçado no campo das diferenças de compósitos (fig. 6c). Nesta última figura pode-se observar uma extensa zona de anomalias positivas da taxa de precipitação diária nas latitudes mais elevadas extendendo-se desde o Sul da Gronelândia até ao Norte da Rússia. De igual forma, mas a latitudes mais baixas, observa-se uma banda de anomalias negativas que se estende desde a costa Leste dos Estados Unidos até à Península Ibérica, prolongando-se de forma menos intensa pela Bacia do Mediterrâneo. Finalmente, uma banda pouco intensa, mas de sinal positivo coerente, pode ser observada no Norte de África e na região Sudeste do Mediterrâneo. Estas bandas de sinal alternadamente positivo e negativo sobre o continente europeu e a Bacia do Mediterrâneo estão de acordo com resultados anteriores (HURRELL e VAN LOON, 1997; OsBorn et al., 1999; Gomes, 2001).

A variabilidade espacio-temporal do campo da precipitação é essencialmente função de dois factores: a disponibilidade em vapor de água e as condições que facilitem a condensação desse mesmo vapor de água. A água precipitável é considerada um bom índice do primeiro factor, pois corresponde à totalidade do vapor de água que se encontra no interior de uma coluna vertical da atmosfera. Assim, representaram-se os campos de anomalias de água precipitável para meses de índice NAO elevado e de índice NAO baixo nas figuras 7a e 7b, respectivamente. Ao contrário da taxa de precipitação diária o impacte da NAO no campo da água precipitável é caracterizado por bandas não zonais de valores positivos e negativos. Este facto é realçado no gráfico relativo às diferenças de compósitos (fig. 7c) onde uma extensa banda positiva, de orientação Sudoeste-Nordeste, surge entre o Sul da Terra Nova e o Norte da Rússia apresentando valores máximos sobre a Irlanda e o Sul da Escandinávia. Esta banda diagonal encontra-se ladeada por duas zonas de sinal negativo, uma delas concentrada entre a Terra Nova e a Gronelândia, e a outra, mais a Sul, estendendo-se desde o Atlântico subtropical até ao Médio Oriente e englobando toda a Bacia do Mediterrâneo. Por outro lado, é sabido que o vapor de água contido numa coluna se encontra bem relacionado com o campo da temperatura dessa mesma coluna. Assim, apesar de os padrões de larga escala da figura 7 serem diferentes dos padrões equivalentes da taxa de precipitação (fig. 6), já são consideravelmente mais parecidos com os correspondentes padrões das figuras relativas às temperaturas máxima (fig. 3) e mínima (fig. 4). 
A condensação da água precipitável requer mecanismos que forcem movimentos verticais; estes mecanismos estão usualmente associados à convergência de ar nos níveis baixos da atmosfera e correspondente circulação ciclónica (vorticidade positiva). O campo da vorticidade (calculado a partir dos compósitos mensais dos campos dos ventos a $10 \mathrm{~m}$ ) indica claramente que grande parte da resposta da taxa de precipitação a situações de índice NAO elevado (fig. 6a) e índice NAO baixo (fig. 6b) corresponde às zonas com anomalias mais intensas do campo da vorticidade. Nestas duas figuras, as isolinhas positivas (negativas) do campo da vorticidade encontram-se representadas a linha contínua (tracejada). É possível verificar que os valores máximos da vorticidade positiva (negativa) se encontram localizados a poucos graus a Norte da região com valores superiores (inferiores) à média da taxa de precipitação. Este deslocamento para Norte é perfeitamente compatível com a típica configuração das perturbações sinópticas das latitudes médias, onde o centro das baixas pressões se encontra posicionado um pouco a Norte das respectivas frentes, sendo estas as principais responsáveis pela precipitação observada em consequência dos intensos movimentos verticais. Em resumo, as anomalias da taxa de precipitação podem ser explicadas, no essencial, em termos do campo anómalo da vorticidade e da correspondente circulação média associada (fig. 6) e, em menor grau, como consequência do conteúdo de água na atmosfera (fig. 7). Este resultado vem igualmente confirmar a relevância dos dias ciclónicos no regime de precipitação da Península Ibérica (Trigo e DACAMARA, 2000) e a sua associação à NAO (Trigo et al., 2002).

\section{IMPACTE DA NAO NA PRECIPITAÇÃO E NOS CAUDAIS DOS RIOS IBÉRICOS}

Para um estudo mais pormenorizado do efeito da NAO no campo da precipitação sobre a Península Ibérica, é conveniente levar a cabo uma análise semelhante com base em valores de dados registados em udómetros. Uma equipa de investigadores da Climatic Research Unit (Universidade de East Anglia, Norwich, Reino Unido) produziu uma nova climatologia de alta resolução $\left(0.5^{\circ}\right.$ latitude por $0.5^{\circ}$ longitude) relativa a seis variáveis distintas com base em valores observados em estações meteorológicas. Esta climatologia foi definida para todo o globo (mas unicamente sobre os continentes) e para um período relativamente extenso: 1901-1995 (NEw et al., 1999). No caso do campo de precipitação para a Europa, esta base revelou possuir uma boa qualidade (NEw et al., 2000).

A figura 8 representa, à semelhança das figuras anteriores, compósitos dos campos de anomalias da precipitação invernal (Dezembro a Março), para a zona da Península Ibérica e para o período compreendido entre de 1901 e 1995. Os compósitos relativos a meses com índice NAO elevado (baixo) podem ser observados na figura 8a (fig. 8b). A diferença dos dois compósitos pode ser 

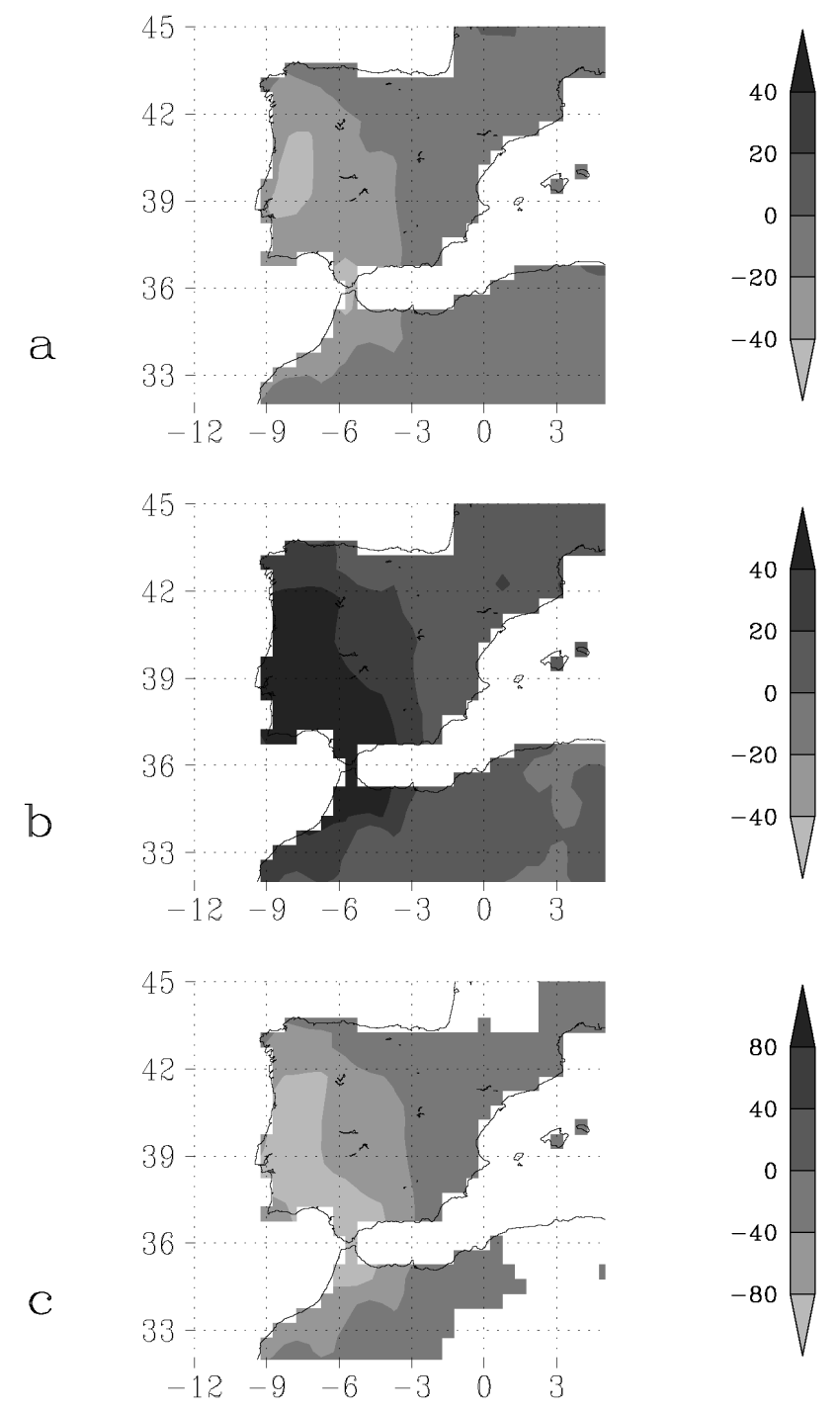

Fig. 8 - Compósitos do campo de anomalias da precipitação mensal (mm/mês) na zona da Península Ibérica, para os meses de Inverno (DJFM) relativos ao período 1901-1995: (a) índice NAO $>1.0$, (b) índice NAO $<-1$ e (c) diferença entre os dois compósitos (representada apenas se for estatisticamente significativa ao nível de 5\%).

Fig. 8 - Precipitation anomaly fields ( $\mathrm{mm} / \mathrm{month})$ over Iberia for winter months (DJFM) of the 1901-1995 period: (a) high NAO index >1.0, (b) low NAO index $<-1.0$ and $(c)$ their difference (represented only if significant at the $5 \%$ level). 
observada na figura 8c, estando unicamente representadas as zonas onde essa diferença é estatisticamente significativa ao nível de 5\% (calculado através de um teste $t$-student para a hipótese nula de as médias serem iguais). Tal como seria de esperar, existe para a zona da Península Ibérica uma forte semelhança com as correspondentes figuras relativas à taxa de precipitação (figs. 6a, 6b e 6c). Assim, continua a verificar-se que o impacte da NAO no campo da precipitação observada é mais intenso nas zonas Oeste (Portugal) e Sul (Andaluzia) da Península, apresentando, no entanto, um prolongamento para Marrocos mais evidente que no campo da taxa de precipitação. Estes resultados vão ao encontro de estudos anteriores realizados por autores que calcularam o coeficiente de correlação da precipitação invernal com o correspondente índice NAO (Rodó et al., 1997; Gomes, 2001).

Tendo em vista a quantificação da influência real da NAO no regime fluvial dos rios, foram utilizados dados hidrométricos de estações representadas na figura 9 por pequenos pontos, respectivamente Pocinho (rio Douro), Vila Velha do Rodão (rio Tejo) e Pulo do Lobo (rio Guadiana). Os períodos utilizados variam em função da disponibilidade de dados; assim o caudal do rio Douro é referente ao período 1922-1997 (76 anos), para o Tejo é relativo a 1901-1989 (com interrupção entre 1936 e 1939, período para o qual não há dados) e para o Guadiana corresponde ao período 1947-1990 (44 anos). Para facilitar a comparação dos gráficos relativos aos diversos rios, os dados foram normalizados (eixo das ordenadas) e todos apresentam o período completo compreendido entre o ano 1900 e o ano 2000 (eixo das abcissas). Uma comparação simples entre os caudais mensais para anos caracterizados por índices elevados (curva a ponteado) e índices baixos (curva a tracejado) da NAO indicam diferenças bastante apreciáveis (figs. 10a, 11a e 12a). De facto, entre os meses de Janeiro e Abril, as diferenças entre o caudal mensal dos dois compósitos são estatisticamente significativas a $1 \%$. Tendo em conta a elevada persistência das séries hidrológicas, optou-se de seguida por agrupar, num único índice invernal, os índices mensais, quer da NAO quer dos caudais, relativos aos meses compreendidos entre Dezembro e Março. Gráficos da variação interanual do caudal invernal e do correspondente índice NAO permitem constatar para todos os três rios (figs. 10b, 11b e 12b) que Invernos com elevado índice NAO são, em geral, caracterizados por valores de caudal abaixo da média (e vice-versa), sendo os respectivos coeficientes de correlação sempre significativos a $1 \%$. São ainda de salientar os seguintes dois aspectos:

a) O coeficiente de correlação do caudal do rio Tejo para o último período (1973-1988) é superior (em módulo) ao valor do mesmo coeficiente para os restantes dois períodos considerados, onde é da ordem dos 0.5 (1901-1935 e 1939-1972). Este facto é concordante com o aumento da (anti) correlação entre o índice da NAO e o campo da precipitação, a partir dos anos 60 para o Sul da Península Ibérica, tal como foi já referido por alguns autores (RoDó, 1997). 
b) Apesar do coeficiente de correlação entre o índice da NAO e o caudal do rio Guadiana ser elevado $(\mathrm{R}=-0.64)$ para o período de 44 anos considerado (1947-1990), verifica-se que, a partir do início dos anos 80 , o caudal do rio deixa de variar com a amplitude que seria de esperar face às importantes alterações observadas do índice da NAO. Tal facto parece ficar a dever-se à grande capacidade de armazenamento de água que as

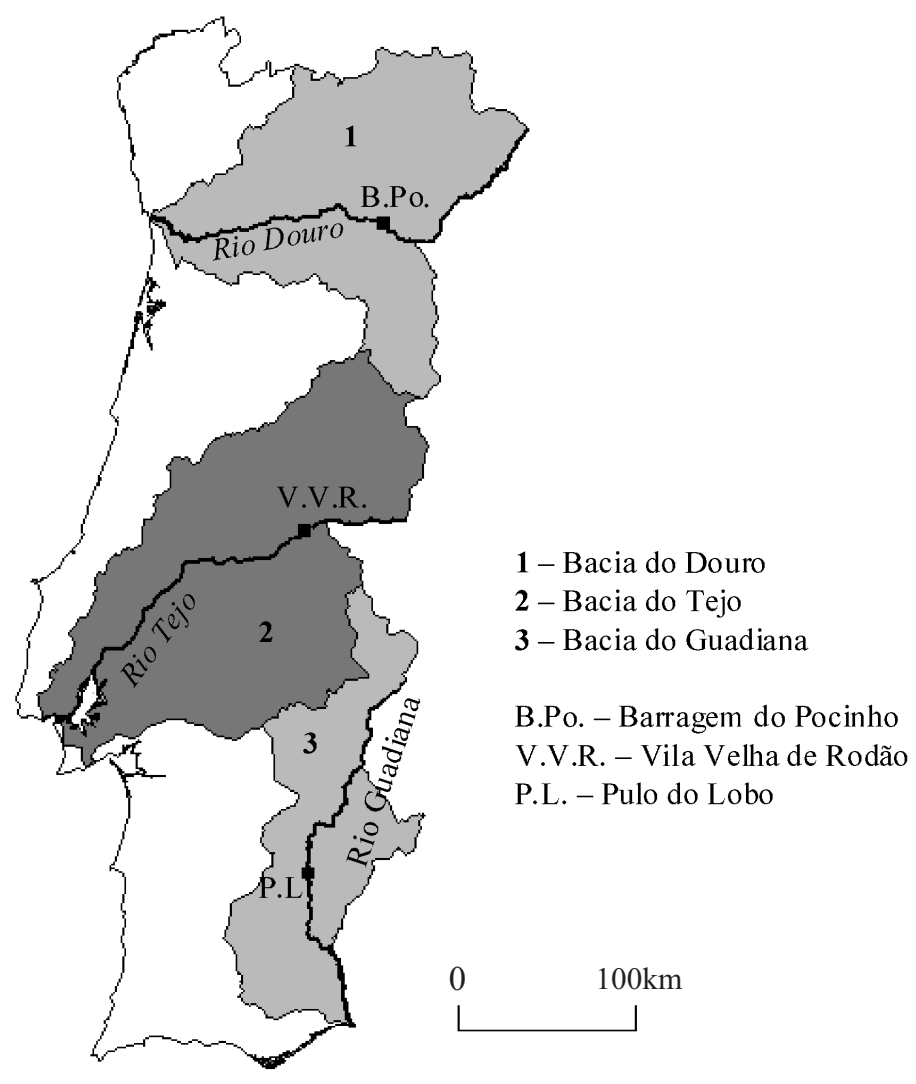

Fig. 9 - Localização das três bacias hidrográficas internacionais estudadas, podendo observar-se as respectivas secções em território português. Os pequenos pontos representam as estações hidrométricas onde foi registado o caudal relativo a cada uma das bacias.

Fig. 9 -Location of the three river basins under consideration, only the Portuguese section of these river basins is represented. Small black dots show the location of river flow gauges used in each basin. 
barragens espanholas construídas nas décadas de 60 e 70 vieram proporcionar. Desta forma, e ao contrário do que se passa nos rios Douro e Tejo, o rio Guadiana, na sua secção portuguesa, passou a ser relativamente 'insensível' às variações de fase do índice da NAO.

Estes resultados permitem enquadrar o problema da elevada variabilidade interanual de caudal que se regista no regime de quase todos os rios ibéricos, em especial nas zonas mais a Sul da Península. Recentemente, RAmos e ReIS (2001) analisaram o comportamento hidrológico dos mesmos três rios aqui considerados, isto é, os rios Douro, Tejo e Guadiana, tendo comprovado que à diminuição do caudal médio do Douro para o Tejo e deste para o Guadiana corresponde um aumento igualmente significativo no índice de irregularidade dos caudais. Estes autores mostram ainda que a construção das grandes barragens no rio Tejo a partir dos anos 50 provocou uma significativa diminuição dos caudais máximos instantâneos. No entanto, as figuras $10 \mathrm{~b}, 11 \mathrm{~b}$ e $12 \mathrm{~b}$ mostram que ao nível do caudal médio sazonal (média do caudal mensal de Dezembro a Março) tal impacte, a existir, é de menor magnitude, excepto para o rio Guadiana, onde como já referimos aparenta ser importante.

Se se considerar o volume de água relativo ao ano hidrológico completo e integrado para todos os rios portugueses com barragens possuindo capacidade de produção de energia hidroeléctrica, verifica-se que o caudal anual varia, aproximadamente, entre anos secos e anos húmidos, por um factor de 3 (COLlares PEREIRA, 1998). Tal variação acarreta uma enorme variabilidade interanual da produção eléctrica de origem hídrica em Portugal, apresentando esta um valor médio da ordem dos $11 \mathrm{TWh}$, mas que varia tipicamente entre os $16 \mathrm{TWh}$ nos anos húmidos (índice NAO baixo) e apenas 6TWh nos anos secos (índice NAO elevado). Portugal (e Espanha) juntam-se assim a um conjunto de países para os quais foi recentemente comprovada a enorme relevância da NAO na produção de energia hidroeléctrica, como são os casos da Turquia (Cullen e DEMENOCAL, 2000) e da Noruega (CHERry et al., 2000).

Neste artigo julgamos ter caracterizado, ainda que de uma forma sucinta, os principais aspectos do impacte espacio-temporal da Oscilação do Atlântico Norte (NAO) no clima de todo o continente europeu. Em particular, apresentámos de forma quantificada a magnitude da influência da NAO no campo da precipitação no continente europeu e na Península Ibérica, bem como no regime fluvial dos principais rios internacionais desta região. Estes resultados permitem evidenciar as enormes vantagens na gestão de recursos hídricos, quer para o sector da produção de energia hidroeléctrica, quer para o sector agrícola, que os esquemas de previsão do índice da NAO poderão vir a proporcionar num futuro próximo (WeDGBRow et al., 2002). 

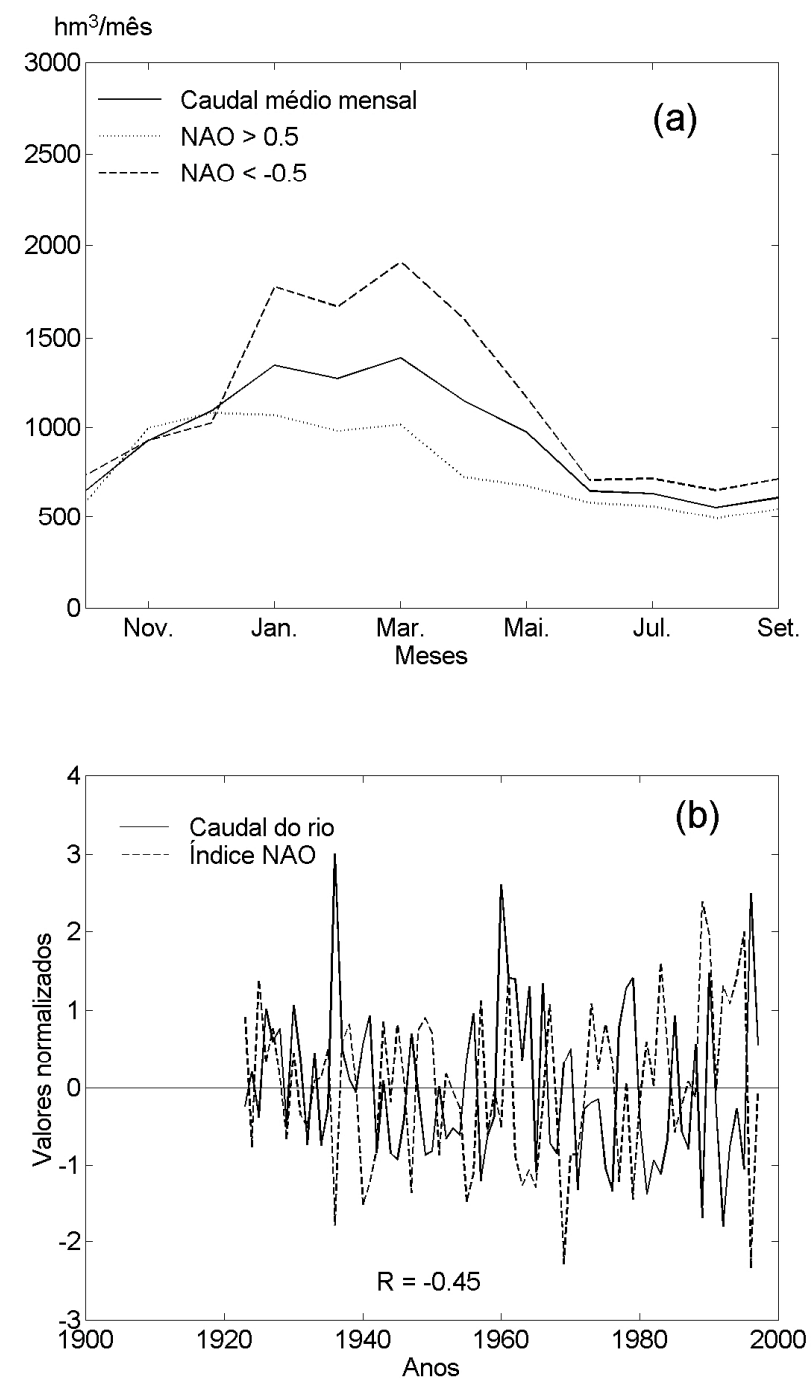

Fig. 10 - (a) Caudal médio mensal do rio Douro no Pocinho para Invernos com índice NAO elevado (curva a ponteado), índice NAO baixo (curva a tracejado) e para a climatologia (curva a cheio); (b) Variabilidade interanual do caudal médio de Inverno (curva a cheio) e do correspondente índice NAO (curva a tracejado) para o rio Douro no Pocinho. Ambas as curvas foram normalizadas.

Fig. 10 - (a) Monthly river flow of river Douro at Pocinho for winters with high NAO index (dotted curve), for winters with low NAO index (dashed curve) and for the average winter (solid line); (b) Interannual variability of the mean winter river flow (solid curve), for river Douro at Pocinho, and the corresponding winter NAO index (dashed curve); both curves have been normalised and so are dimensionless. 

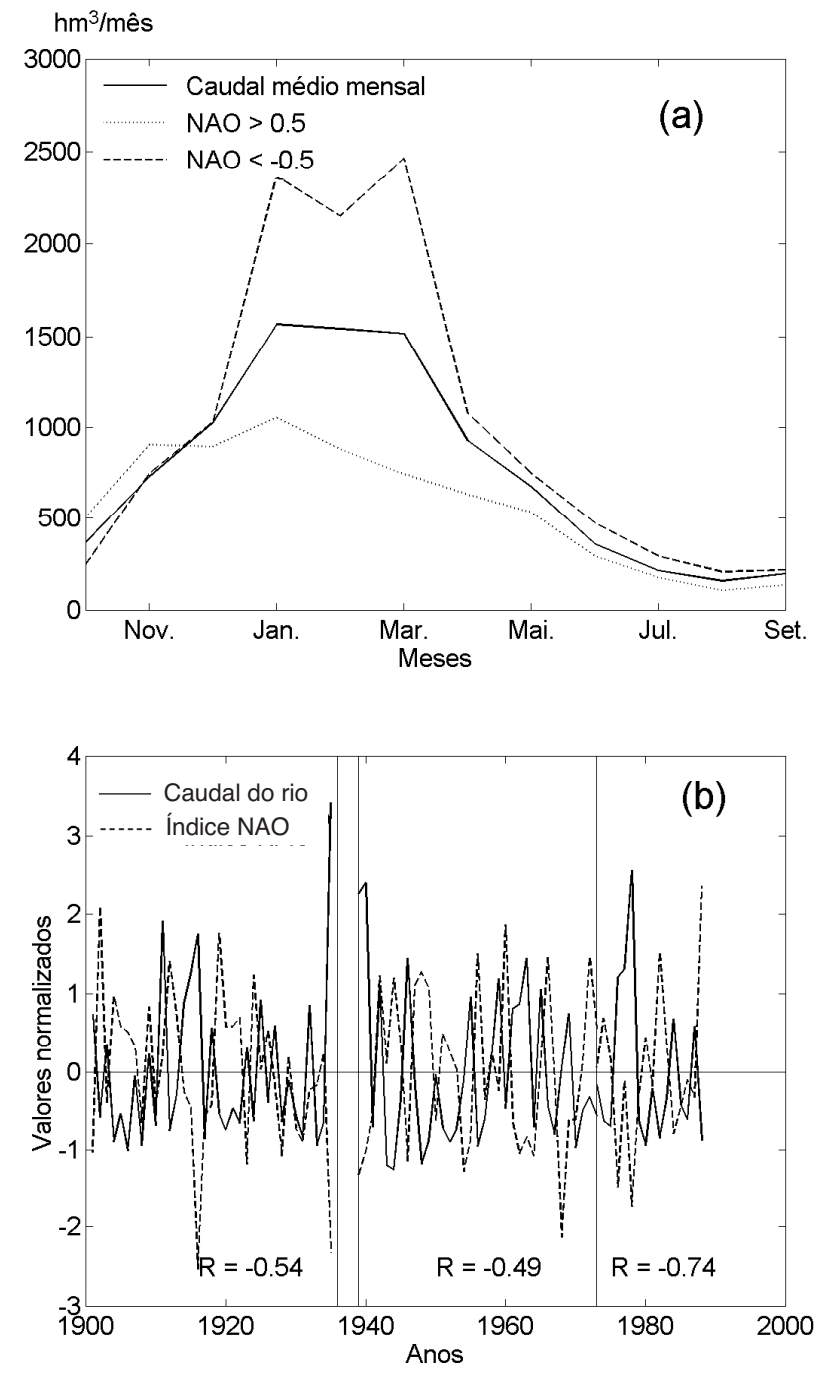

Fig. 11 - Tal como na fig. 10, mas relativo ao rio Tejo em Vila Velha de Rodão. Não existem dados de caudal para os anos de 1936 a 1939.

Fig. 11 - The same as in fig. 10, but for river Tagus at Vila Velha de Rodão. There is no available data for the period between 1936 and 1939. 

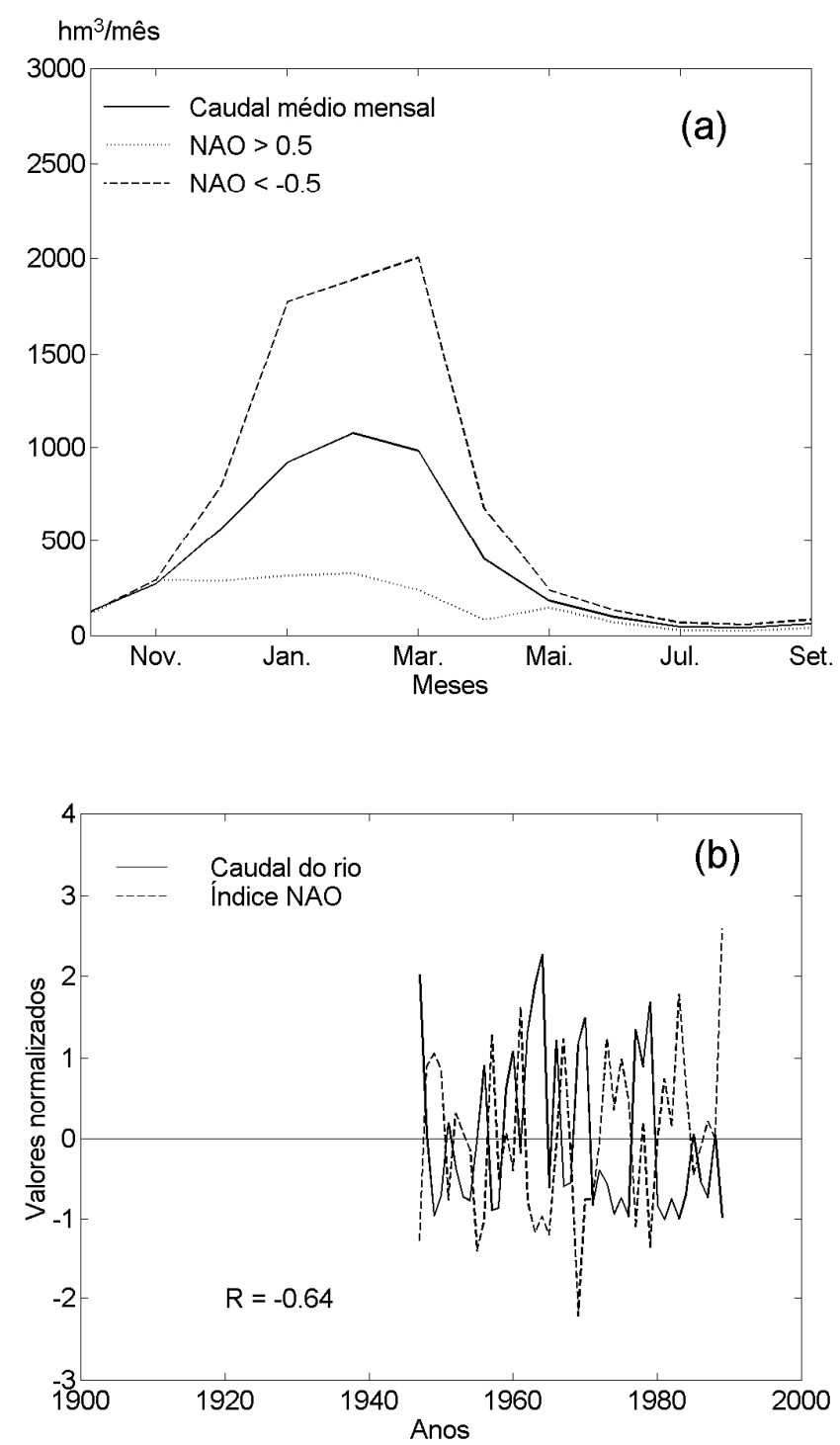

Fig. 12 - Tal como na fig. 10, mas relativo ao rio Guadiana no Pulo do Lobo. Fig. 12 - The same as in fig. 10, but for river Guadiana at Pulo do Lobo. 


\section{AGRADECIMENTOS}

Os autores agradecem à Dr. ${ }^{\text {a }}$ Isabel Trigo o algoritmo para os campos das trajectórias de depressões. Agradecem igualmente ao Instituto Nacional da Água (INAG) e ao Eng. Rui Pestana (Rede Eléctrica Nacional) por terem fornecido os dados relativos aos caudais de rios portugueses. Agradecemos à editora Inter-Research a permissão de utilizar algumas figuras do artigo: TRIGO, R. M., Osborn, T. J. e Corte-Real, J. (2002), «The North Atlantic Oscillation influence on Europe: climate impacts and associated physical mechanisms» da revista Climate Research, 20, 9-17. Finalmente, os autores agradecem à Dr. ${ }^{a}$ Célia Gouveia a sua preciosa ajuda na parte gráfica.

\section{BIBLIOGRAFIA}

Barnston, A. G.; Livezey, R. E. (1987) - Classification, Seasonality and Persistence of LowFrequency Atmospheric Circulation Patterns. Mon. Wea. Rev., 115: 1083-1127.

Cherry, J.; Cullen, H. M.; Visbeck, M. (2000) - Impacts of the North Atlantic Oscillation on the energy sector: the Scandinavian example. American Geophysical Union Chapman Conference, Ourense, Spain.

Collares Pereira, M. (1998) - Energias Renováveis, a Opção Inadiável. Sociedade Portuguesa de Energia Solar.

Cullen, H. M.; DeMenocal, P. B. (2000)-North Atlantic Influence on Tigris-Euphrates Streamflow. Int. J. Climatol., 20: 853-863.

DeWeaver, E.; Nigam, S. (2000) - Zonal-Eddy dynamics of the North Atlantic Oscillation. J. Climate, 13: 3893-3914.

Gomes, P. T. (2001) - Relationships between Iberian rainfall variability and the North Atlantic Oscillation. In M. BRunet India and D. López Bonilo (edit), Detecting and modelling Regional Climate change, Springer Verlag: 377-387.

Hurrell, J. W. (1995) - Decadal trends in the North Atlantic Oscillation: regional temperatures and precipitation. Science, 269: 676-679.

HurRell, J. W. (1996) - Influence of variations in extratropical wintertime teleconnections on Northern Hemisphere temperature. Geophys. Res. Lett., 23: 665-668.

Hurrell, J. W.; VAn Loon, H. (1997) - Decadal variations in climate associated with the North Atlantic Oscillation. Clim. Change, 36: 301-326.

Jones, P. D.; Jonsson, T.; Wheeler D. (1997) - Extension to the North Atlantic Oscillation using instrumental pressure observations from Gibraltar and south-west Iceland. Int. J. Climatol., 17: 1433-1450.

Kalnay, E.; Kanamitsu, M.; Kistler, R.; Colins, W.; Deaven, D.; Gandin, L.; Iredell, M.; Saha, S.; White, G.; Wollen, J.; Zhu, Y.; Cheliah, M.; EbisuZaki, W.; Higgins, W.; Janowiak, J.; Mo, K. C.; Ropelewski, C.; Wang, J.; LeetmaA, A.; Reynolds, R.; Jenne; JosePh, D. (1996) - The NCEP/NCAR 40-years reanalyses project. Bull. Am. Meteorol. Soc., 77: 437-471. 
Mehta, V. M.; Suarez, M. J.; Manganello, J. V. (2000) - Oceanic influence on the North Atlantic Oscillation and associated northern hemisphere climate variations: 1959-1993. Geophy. Res. Lett., 27: 121-124.

MurRay, R. J.; SimmondS, I. (1991) - A numerical scheme for tracking cyclones centres from digital data. Part I: Development and operation of the scheme. Aust. Meteor. Mag., 39: 155-166.

New, M. G.; Hulme, M.; Jones, P. D. (1999) - Representing twentieth-century space-time climate variability. Part I: Development of a 1961-90 mean monthly terrestrial climatology. J. Climate, 12: 829-856.

New, M. G.; Hulme, M.; Jones, P. D. (2000) - Representing twentieth-century space-time climate variability. Part II: Development of a 1901-95 monthly grids of terrestrial surface climate. J. Climate, 13: 2217-2238.

Osborn, T. J.; Briffa, K. R.; TetT, S. F. B.; Jones, P. D.; Trigo, R. M. (1999) - Evaluation of the North Atlantic Oscillation as simulated by a climate model. Climate Dyn., 15: 685-702.

Qian, B.; Corte-Real, J.; XU, H. (2000) - Is the North Atlantic Oscillation the most important atmospheric pattern for precipitation in Europe? J. Geophy. Res., 105: 11901-11910.

Ramos C.; Reis, E. (2001) - As cheias em Portugal em diferentes tipos de bacias hidrográficas. Finisterra - Revista Portuguesa de Geografia, Lisboa, XXXVI (71): 61-82.

Rodó, X.; BAERT, E.; Comin, F. A. (1997) - Variations in seasonal rainfall in Southern Europe during the present century: relationships with the North Atlantic Oscillation and the El Niño-Southern Oscillation. Climate Dyn., 13: 275-284.

Rodwell, M. J.; Rowell, D. P.; Folland, C. K. (1999) - Oceanic forcing of the wintertime North Atlantic Oscillation and European Climate. Nature, 398: 320-323.

Rogers, J. C. (1984) - The association between the North Atlantic Oscillation and the Southern Oscillation in the Northern Hemisphere. Mon. Wea. Rev., 112: 1999-2015.

Rogers, J. C. (1990) - Patterns of low-frequency monthly sea level pressure variability (1899-1986) and associated wave cyclone frequency. J. Climate, 3:1364-1379.

Rogers, J. C. (1997) - North Atlantic storm track variability and its association to the North Atlantic Oscillation and climate variability of Northern Europe. J. Climate, 10: 1635-1647.

SARAVANAN, R. (1998) - Atmospheric low-frequency variability and its relationship to midlatitude SST variability: studies using NCAR climate system model. J. Climate, 11: 1386-1404.

Serreze, M. C.; CARSE, F.; BARRY, R. G.; Rogers, J. C. (1997) - Icelandic Low cyclone activity: climatological features, linkages with the NAO, and relationships with recent changes in the Northern Hemisphere circulation. J. Climate, 10: 453-464.

Stendel, M.; ARPE, K. (1997) - Evaluation of the hydrological Cycle in Re-Analysis and Observations. ECMWF Re-Analysis Validation Reports - Part 1. ECMWF RE-Analysis Project Report Series 6.

Thompson, D. W. J.; Wallace, J. M. (1998) - The Arctic Oscillation signature in the wintertime geopotential height and temperature fields. Geophys. Res. Lett., 25: 1297-1300.

Thompson, D. W. J.; Wallace, J. M (2001) - Regional Climate Impacts of the Northern Hemisphere Annular Mode and Associated Climate Trends. Science, 293: 85-89. 
Trigo, I. F.; Davies, T. D.; Bigg, G. R. (1999) - Objective climatology of cyclones in the Mediterranean region. J. Climate, 12: 1685-1696.

Trigo, R. M.; DaCamara, C. C. (2000) - Circulation Weather Types and their impact on the precipitation regime in Portugal. Int. J. of Climatol., 20: 1559-1581.

Trigo, R. M.; Osborn, T. J.; Corte-Real, J. (2002) - The North Atlantic Oscillation influence on Europe: climate impacts and associated physical mechanisms. Clim. Res., 20: 9-17.

Ulbrich, U.; Christoph, M.; Pinto, J.G.; Corte-Real, J. (1999) - Dependence of winter precipitation over Portugal on NAO and baroclinic wave activity. Int. J. Climatol., 19: 379-390.

Ulbrich, U.; Christoph, M. (1999) - A shift in the NAO and increasing storm track activity over Europe due to anthropogenic greenhouse gas. Climate Dyn., 15: 551-559.

WALKer, G. T. (1924) - Correlations in seasonal variations of weather. IX Mem. Ind. Meteorol. Dept., 24: 275-332.

Walker, G. T.; Bliss, E. W. (1932) - World Weather, V Mem. Roy. Meteorol. Soc., 4: 53-84.

Wallace, J. M.; GutZler, D. S. (1981) - Teleconnections in the geopotential height field during the Northern Hemisphere winter. Mon. Wea. Rev., 109: 784-812.

Wallace, J. M.; Zhang, Y.; Renwick, J. A. (1995) - Dynamic contributions to the hemispheric mean temperature trends. Science, 270: 780-783.

Wallace, J. M. (2000) - North Atlantic Oscillation/annular mode: Two paradigms-one phenomenon. Q. J. R. Meteorol. Soc., 126: 791-805.

Wedgbrow, C. S.; Wilby, R. L.; Fox, H. R.; O’Hare, G. (2002) - Prospects for Seasonal forecasting of summer drought and low river flow anomalies in England and Wales. Int. J. Climatol., 22: 219-236.

WidmanN, M.; BRETHERTON, C. S. (2000) - Validation of mesoscale precipitation in the NCEP reanalysis using a new gridcell data set for the northwestern United States. J. Climate, 13: $1936-1950$.

Wilby, R. L.; O'Hare, G.; Barnsley, N. (1997) - The North Atlantic Oscillation and the British Isles climate variability 1865-1995. Weather, 52: 266-276. 